\title{
Ulcerative tracheo-oesophageal fistula during treatment by tracheostomy and intermittent positive pressure ventilation ${ }^{1}$
}

\author{
H. R. S. HA R LE Y \\ Sully Hospital, Sully, Penarth, Glam.
}

\begin{abstract}
Forty-four collected cases of ulcerative tracheo-oesophageal fistula following tracheostomy and assisted ventilation are reviewed. The condition followed this form of treatment in $0.5 \%$ of cases and must be distinguished from fistulae caused by accident or surgery, and also from laryngotracheal paralysis or dysfunction. The symptomatology, diagnosis, and treatment are discussed in detail. Spontaneous cure of fistulae is rare, and operative closure should be the aim. In one patient in six, surgical closure is excluded by rapid death. When surgery is possible its timing requires critical judgement. Factors requiring assessment are the condition of the patient and of the tissues around the fistula, the necessity to continue assisted ventilation, and the ability to control nutrition, tracheal aspiration from the mouth or stomach, and pulmonary infection. The mortality of those who did not die too rapidly to receive treatment was $61 \%$ without surgery and $45.5 \%$ with surgery.
\end{abstract}

Tracheo-oesophageal fistula occurring after the institution of tracheostomy and intermittent positive pressure ventilation (IPPV) can be classified under three headings, namely, traumatic (accidental), surgical (iatrogenic), and ulcerative.

Traumatic fistulae occur as the result of chest injury, either closed (Stephens, 1965; Killen and Collins, 1965; Judd and Dubuque, 1968; Støren and Vasli, 1968; Chapman and Braun, 1970) or open. Such an aetiology must be considered whenever assisted ventilation is used for treating crush injuries, as the tracheo-oesophageal fistula does not manifest itself clinically until after a latent period, usually of three to five days. Such traumatic fistulae are rare. Chapman and Braun (1970) collected 27 cases from the literature and added one of their own. Surgical injury may occur if, on opening the trachea while performing tracheostomy, the scalpel incises the posterior wall of the treachea and the anterior wall of the oesophagus (Watts, 1963; Nicholas, Dupon, Guillon, and Cornet, 1967). This occasionally happens, and may be unrecognized, when the operation is done in extenuating circumstances, especially in children, in whom the parts are small and soft, or in

1Based on a paper delivered to the Thoracic Society Summer Meeting 1971 older subjects whose cartilage rings are calcified (Watts, 1963). The posterior wall of the trachea and anterior wall of the oesophagus may also be damaged during insertion of the tracheostomy tube (Nicolas et al., 1967)

This paper is concerned solely with ulcerative fistulae, and the other two varieties will be discussed only with regard to differential diagnosis. ULCERATIVE TRACHEO-OESOPHAGEAL FISTULA AFTER
TRACHEOSTOMY AND IPPV

INCIDENCE I have collected 38 cases from the $\mathcal{N}$ literature and six through the courtesy of col- $N$ leagues, giving a total of 44 cases (Table I).

In 29 of the 44 cases the number of tracheostomies performed is known so that the percentage incidence can be calculated. This is shown in Table I. These 29 cases occurred after 5,865 tracheostomies, an incidence of $0.49 \%$. I conclude 7 that 5,772 of these patients were treated by IPPV so that the incidence for this method of treatment $\vec{D}$ is $0.50 \%$. The patients of Campbell (1968) were $\frac{\overrightarrow{\mathbb{D}}}{\mathrm{d}}$ ventilated through either a cuffed tracheostomy tube or a cuffed endotracheal tube. The numbers of each are not given by the author and so they 
TABLE I

INCIDENCE OF ULCERATIVE TRACHEO-OESOPHAGEAL FISTULA FOLLOWING TRACHEOSTOMY AND IPPV

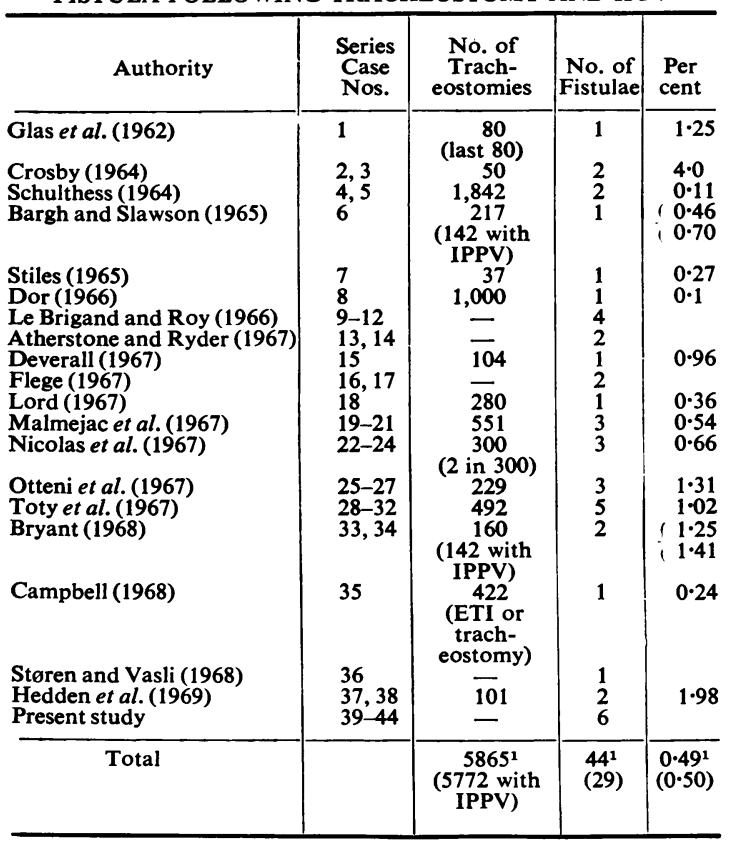

${ }^{1}$ See text for explanation of figures

ETI =endotracheal tube

have all been grouped under tracheostomy for the purpose of this analysis.

In all reports accompanied by case histories tracheo-oesophageal fistula followed treatment by intermittent positive pressure ventilation. The conditions for which tracheostomy and assisted respiration were employed were:
Not known

Neurological disease

\section{Tetanus}

Flail chest, with or without other injuries

Chronic respiratory disease

Open heart surgery

Other conditions
In two of the cases of injury assisted ventilation was necessary because of traumatic quadriplegia, and in another because of paraplegia. Thus 14 cases were treated for neurological defects, and one for a neurological defect plus a flail chest. In addition three were treated for tetanus. Thus 17 patients were treated for neurological problems, one of whom also had a flail chest.
PATHOGENESIS Ulcerative tracheo-oesophageal fistula caused by tracheostomy and assisted ventilation occurs at the site of the cuff or tip of the tracheostomy tube, usually the former (vide infra), and their aetiology is the same as that of tracheal stenosis occurring at these sites. The pathology and pathogenesis of the tracheal damage, together with its prevention, have been discussed comprehensively elsewhere (Harley, 1971) and the reader is referred to that article for full details and bibliography.

Damage to the trachea is initiated mechanically by pressure and movement inflicted by the inflated cuff or tip of the tracheostomy tube, and is aggravated by the infection which inevitably follows ulceration of the mucosa in these circumstances. The importance of infection cannot be over-emphasized (Harley, 1971), and has been stressed in the context of tracheo-oesophageal fistula by a number of workers (Atherstone and Ryder, 1967; Toty, Hertzog, Diane, and Aboudi, 1967; Nicolas et al., 1967; Støren and Vasli, 1968). Other factors such as chemical irritation, hypotension, and antiinflammatory agents, such as steroids or phenylbutazone (Nicolas et al., 1967; Hedden, Ersoz, and Safar, 1969), may further add to the damage caused by pressure-infective necrosis. If ulceration extends through the whole thickness of the membraneous wall of the trachea before a fibrotic reaction, leading to stenosis, has had time to occur then a tracheo-oesophageal fistula may result (Harley, 1971). One of the collected cases (case 39) is illustrated (Fig. 1).

Concerning the mechanism of oesophageal damage, I believe, with many others (Johnston, Wright, and Hercus, 1967; Lord, 1967; Hunter, 1967; Toty et al., 1967; and Nicolas et al., 1967), that an ulcerative tracheo-oesophageal fistula of the type under discussion is caused by ulceration of the trachea spreading subsequently into the oesophagus. Nicolas et al. (1967), however, point out that the hypothesis that the oesophagus is the origin of the process leading to a fistula with the trachea cannot be rejected without discussion. Decubitus ulcers of the oesophagus occur in tracheotomized patients, sometimes near the upper end of the oesophagus (Mounier-Kuhn, Gaillard, Garing, and Rebattu, 1958), but if this is initiated by pressure from the tracheostomy tube and its cuff the trachea suffers likewise and it is improbable that oesophageal ulceration can be the only factor in the genesis of tracheo-oesophageal fistula.

The argument that ulceration starts in the trachea, and subsequently extends into the oesophagus, is strongly supported by the fact that 


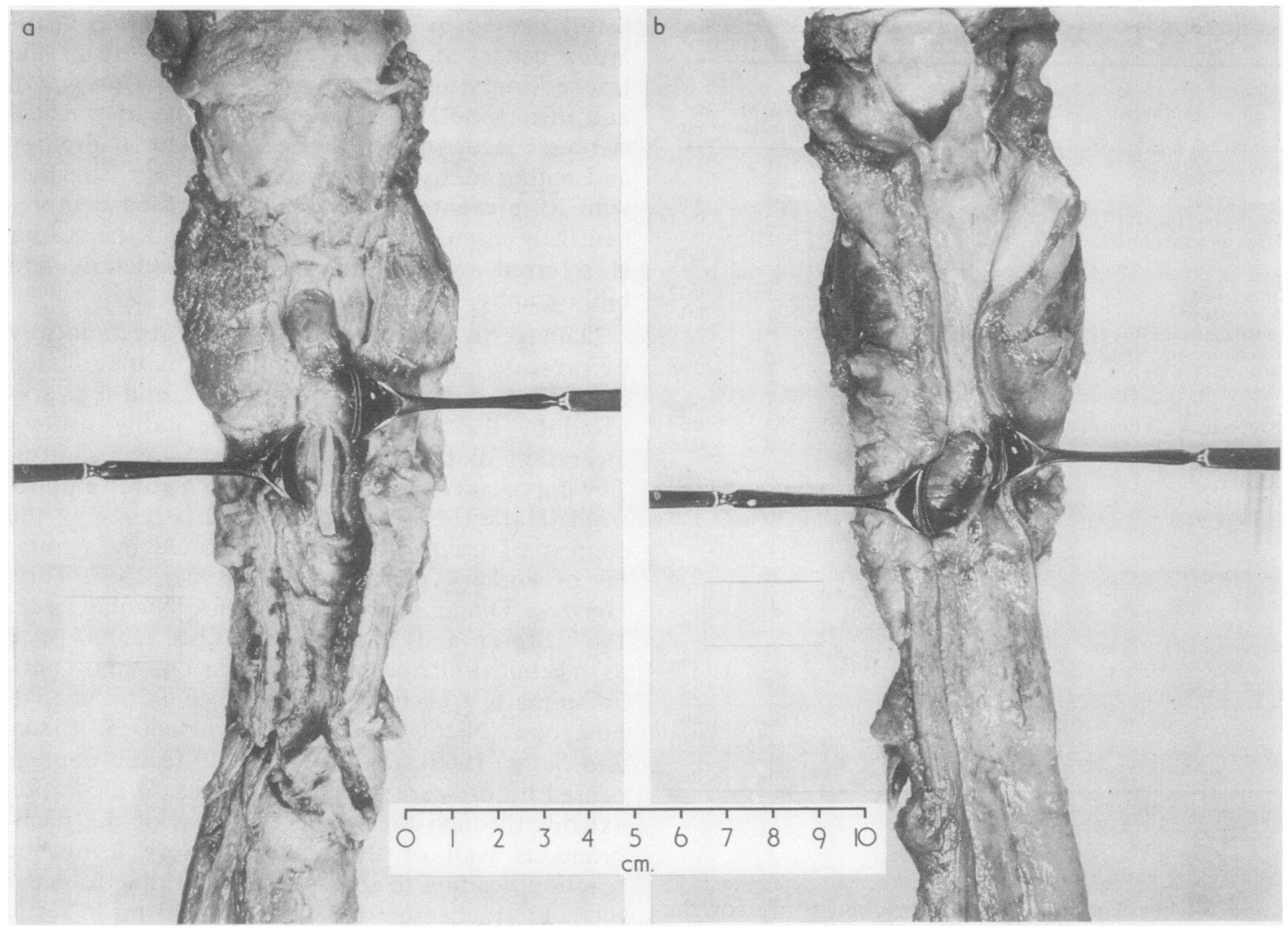

FIG. 1. Case 39. Necropsy specimen showing tracheo-oesophageal fistula from (a) trachea and (b) oesophagus. Courtesy of Dr. D. Ball.

ulceration of the trachea, in patients undergoing treatment by IPPV, is not uncommonly confined to the trachea at the site of the inflated cuff or end of the tracheostomy tube, especially the former, and may be so severe as to cause subsequent stenosis (Harley, 1971). When a tracheo-oesophageal fistula develops it does so precisely at these same sites.

Once the membraneous wall of the trachea yields and ulcerates, the anterior wall of the oesophagus becomes vulnerable to compression between the cuff or tip of the tracheostomy tube and the vertebral column (Flege, 1967; Toty et al., 1967), to the shearing stress of the movements of deglutition and of the tracheostomy tube, and to infection, together with the other factors enumerated as damaging the trachea. At the site of tracheal ulceration the inflammatory reaction occurring in advance of the ulceration welds the trachea and oesophagus together so that ulceration can spread from the former directly to the latter without giving rise to diffuse mediastinitis or pneumomediastinum.

I believe, with Nicolas et al. (1967) and most other workers, that the great majority of tracheooesophageal fistulae are caused by damage inflic- $N$ ted by the inflated cuff rather than by the tip of N the tracheostomy tube, but Le Brigand and Roy $O$ (1966) believe the latter to be the principal cause. Toty et al. (1967) describe, and illustrate diagram- $\frac{\mathscr{C}}{\Phi}$ matically, how the inflated cuff may distend the $\stackrel{?}{?}$ membraneous wall of the trachea into a sac, like 0 a diverticulum, into which it fits. The oesophagus $\overrightarrow{0}$ is caught like a sandwich between the inflated cuff $\mathbb{D}$ and the vertebral column. If chronic irritation and $\vec{D}$ infection weld the trachea and oesophagus together, the end of the tracheostomy tube, or of an aspirating catheter, may then damage or perforate 
the lower margin of the 'diverticulum' and so create a tracheo-oesophageal fistula (Figs. 2 and 3). Toty et al. (1967) consider that the initiating factor is compression and ischaemia caused by the cuff, followed by repeated trauma from the end of the tracheostomy tube and aspirating catheters. In all their patients severe infection and starvation were additional factors.

Other factors may be of considerable importance in leading to oesophageal damage. Thus damage may be caused by resident nasogastric tubes (Nicolas et al., 1967 ; Støren and Vasli, 1968 ; Hedden et al., 1969), especially if they are large and hard. The anterior wall of the oesophagus and the posterior wall of the trachea may be compressed for long periods between such a tube and the inflated cuff (Nicolas et al., 1967), and this compression may be enhanced by the reduced flexibility of their walls occasioned by a firm nasogastric tube (Støren and Vasli, 1968). Nasogastric tubes are frequently used for feeding patients treated by assisted ventilation. Care should be taken to select the smallest and softest tube consistent with adequate function, and to remove it as soon as possible.

Fragility of the tissues of the trachea and oesophagus is thought to be of aetiological importance by French workers. This may be occasioned by age (Nicolas et al., 1967), gastro-oesophageal

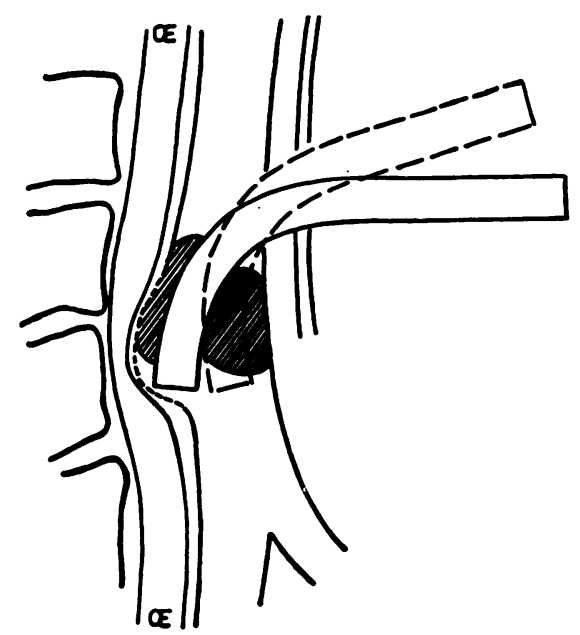

FIG. 2. Distension of trachea by inflated cuff to form $a$ 'diverticulum' adherent to the oesophagus. End of tracheostomy tube may damage lower margin of diverticulum and oesophagus to create a fistula.

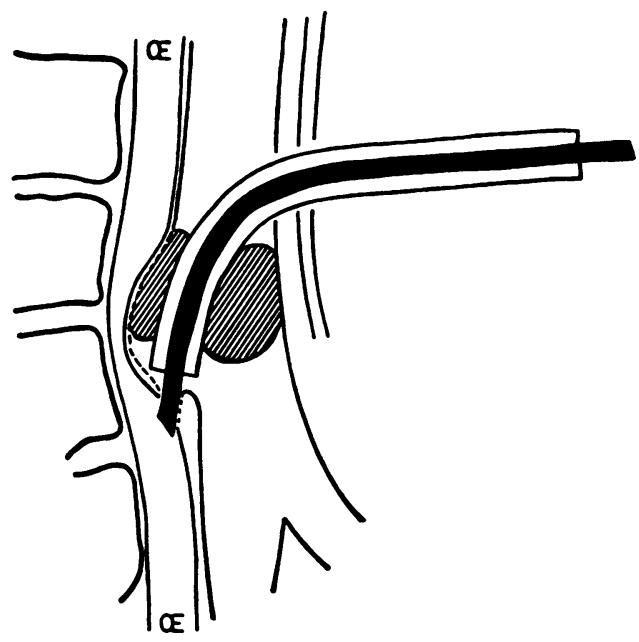

FIG. 3. Damage to lower margin of 'diverticulum' and oesophagus by aspiration cannula to create $a$ fistula. (Figures 2 and 3 are reproduced from Toty et al. (1967) by permission of the authors and the publisher.)

reflux (Le Brigand and Roy, 1966; Dor, 1966; Nicolas et al., 1967), infection and anti-inflammatory drugs, such as steroids (Nicolas et al., 1967; Hedden et al., 1969) or phenylbutazone (Nicolas et al., 1967). Gastro-oesophageal reflux is liable to occur in patients treated by assisted ventilation because of prolonged decubitus, lack of muscle tone, diaphragmatic atony, especially during curarization, and resident nasogastric tubes. Gastric reflux causes oesophagitis and may make the oesophagus more fragile, so favouring its ulceration and the development of a tracheooesophageal fistula (Le Brigand and Roy, 1966; Dor, 1966; Nicolas et al., 1967). Schulthess (1964) and Le Brigand and Roy (1966) believe that trophic lesions may be important and report cases of tracheo-oesophageal fistula occurring in patients undergoing assisted ventilation for Guillain-Barré syndrome and myasthenia gravis. Local damage to the oesophagus by para-oesophageal lymph nodes may also favour the development of a tracheo-oesophageal fistula (Le Brigand and Roy, 1966).

SEX Eighteen of the 44 patients were males and 14 were females. The sex of the remaining 12 is not known. Males, therefore, accounted for $56.25 \%$, and females for $43.75 \%$, of the patients whose sex is known. 
AGE The ages of the patients ranged from 11 to 78 years and were distributed as follows: Age (years)

$\begin{array}{lr}0-10 & 0 \\ 11-20 & 2 \\ 21-30 & 6 \\ 31-40 & 8 \\ 41-50 & 5 \\ 51-60 & 3 \\ 61-70 & 6 \\ 71-80 & 2 \\ \text { ot known } & 12 \\ & -14\end{array}$

There is a wide scatter of ages with a fairly even distribution between 20 and 70 years of age. The condition is not confined to elderly people.

TIME BETWEEN PERFORMING TRACHEOSTOMY AND RECOGNITION OF FISTULA The times ranged from three days to 18 months, the individual times being as follows:

Time

First week

Second week

Third week

Fourth week

Fifth week

Sixth week

Seventh week

Eighth week

Ninth week

Tenth week

Eleventh week

Twelfth week

Three to six months

Six to 12 months

Twelve to 18 months

Not known

Total

It can be seen that in 31 of the 34 cases for which the time was known the tracheooesophageal fistula was recognized in the first 10 weeks after performing tracheostomy, but in only one of these was it recognized in the first week. Twenty of the 34 were recognized during the second, third, and fourth weeks. The condition is thus uncommon during the first week, occurs frequently during the second, third, and fourth weeks, and thereafter occurs with some frequency up to the tenth week. It may occasionally develop after many months.

DURATION OF INTERMITTENT POSITIVE PRESSURE
VENTILATION As far as can be ascertained, the duration of IPPV was the same as the time between performing tracheostomy and recognition of the tracheo-oesophageal fistula, except in three cases in which the particulars of IPPV are unknown, and in two in which the period of IPPV was less than the time between tracheostomy and recognition of the fistula. In one case the times were respectively nine and five weeks, while in the other they were five and two weeks.

SITE OF TRACHEO-OESOPHAGEAL FISTULA As the result of observations made at endoscopy, operation, and necropsy the tracheo-oesophageal fistulae were located relative to the tracheostomy tube and to the lower margin of the tracheal stoma. In a few instances other reference points were used.

Relative to tracheostomy tube
At level of cuff

The findings indicate that the great majority of fistulae occur at the level of the inflated cuff, and I believe that the cuff is primarily responsible for these cases.

Relative to lower margin of tracheal stoma The site of the fistulae varied from just below the tracheal stoma to $4.5 \mathrm{~cm}$ below the stoma. Most $\underset{x}{\stackrel{\nu}{\Perp}}$ of the fistulae were located 1 to $3 \mathrm{~cm}$ below the $\dot{\sigma}$ stoma, the same position at which cuff stenoses occur (Harley, 1971). This site usually places the 8 fistulae at or just below the upper margin of the manubrium sterni, or about half way between 을 the cricoid cartilage and the carina. In the few cases for which measurements were given the fistulae lay between 6 and $8 \mathrm{~cm}$ above the carina.

SIZE OF TRACHEO-OESOPHAGEAL FISTULA The size $N$ of the tracheo-oesophageal fistula was estimated 0 at endoscopy, operation or necropsy in 19 of the 44 cases, in four of them by two of these methods. The findings are as follows:

Size of tracheo-oesophageal fistula $(\mathrm{cm})$ Endoscopy

$0.5 \times 0.5$ to $2.0 \times 2.0$ Operation

$1.0 \times 0.5$ to $4.0 \times 2.0$ Necropsy

$1.0 \times 1.0$ to $5.0 \times 5.0$

It will be noted that the estimated size increases 
under the three headings from above downwards. The size of a tracheo-oesophageal fistula clearly tends to be under-estimated at endoscopy or operation, especially the former. It is, of course, possible that the patients with the large fistulae died. In the two patients in whom measurements were made at necropsy and at either endoscopy or operation, the measurement at necropsy was the same in one case and larger in the other than the measurement made during life.

ASSOCIATED LESIONS CAUSED BY TRACHEOSTOMY AND IPPV Other lesions caused by treatment with assisted ventilation occurred in eight of the 44 patients, as shown:

\begin{tabular}{lc}
\multicolumn{1}{c}{ Associated lesion } & No. \\
Tracheal stenosis & 6 \\
Perforation of innominate artery & 2 \\
Total & $\frac{8}{}$
\end{tabular}

Six patients developed tracheal stenosis as well as tracheo-oesophageal fistulae. Three of these stenoses were stated to be at cuff level. The site of the other three was not given. Only one of the six patients died. The tracheo-oesophageal fistula was repaired in four of the five survivors, and in the fifth it closed spontaneously. The stenosis was treated by maintenance of tracheostomy in one, by recannulation in one (the fatal case), by dilatations in one, in whom it was considered that surgery might be required in the future, and by resection and anastomosis in one. In the remaining two patients the treatment of the stenosis was not recorded.

Two patients developed perforation of the innominate artery in addition to the tracheooesophageal fistula. Both patients died; necropsy in one showed the tracheo-arterial and tracheooesophageal fistulae to be at the same level, namely the site of the cuff.

\section{CLINICAL MANIFESTATIONS OF ULCERATIVE TRACHEO-OESOPHAGEAL FISTULA}

As already indicated, the tracheo-osophageal fistula may manifest itself any time between one week and 18 months after the beginning of treatment, but it usually does so after one to 10 weeks, and especially between the second and fourth weeks.

The condition is usually first recognized by the

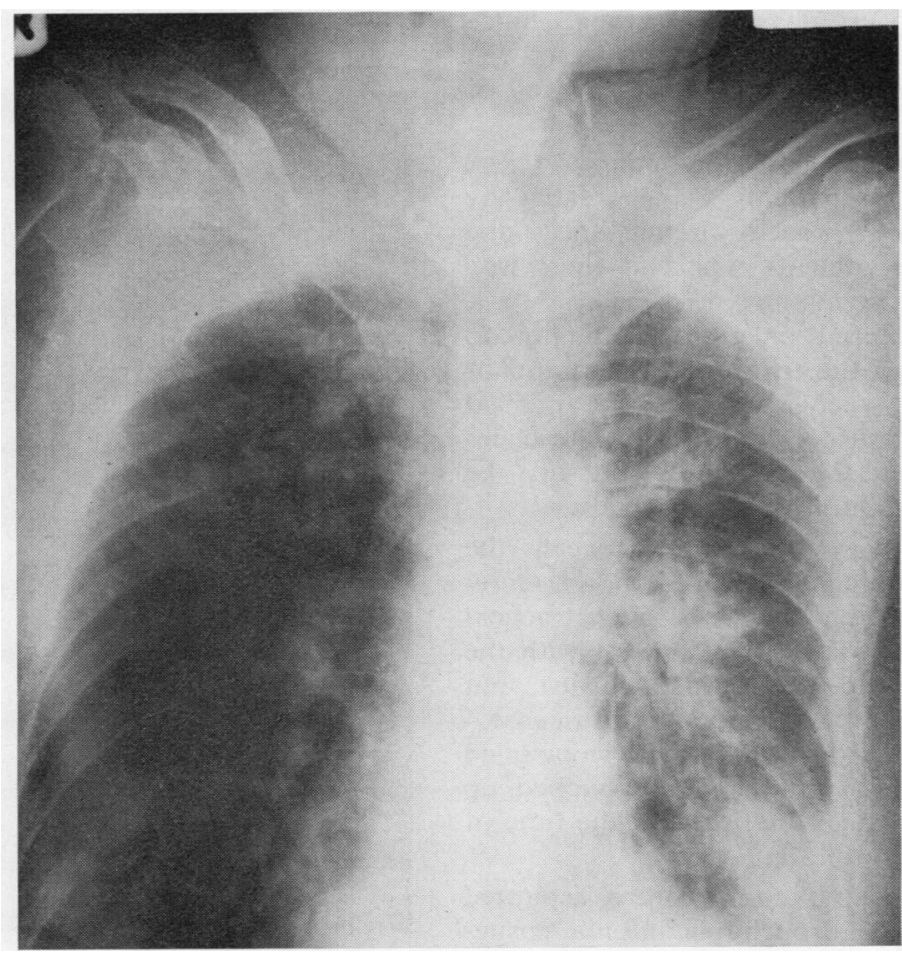

FIG. 4. Case 39. Radiograph of neck, superior mediastinum, and most of thorax, showing large cuff and severe bilateral aspiration pneumonia. 
passage of swallowed material or regurgitated gastric contents through the fistula into the trachea, where its further course will depend upon the relationship of the fistulous opening to the cuff of the tracheostomy tube, and upon whether the cuff is inflated or deflated. When the cuff is inflated it may well occlude either the lower or the upper part of the fistula, or even the whole of it. Should the lower part of the opening be occluded by the inflated cuff then the swallowed or regurgitated material will enter the trachea above the cuff and will flow through the tracheostomy wound around the tube. If the material enters the trachea below the cuff it can both flood the lungs or come out through the tracheostomy tube, for instance during tracheal aspiration. When the cuff is deflated any of these routes may be taken. Occasionally the passage of swallowed material through the fistula occurs only when the cuff is collapsed because inflation of the cuff may seal the communication.

The passage of swallowed material into the trachea produces the characteristic swallow-cough symptom complex or hallmark (Stephens, 1965; Killen and Collins, 1965 ; Chapman and Braun, 1970). This is not likely to occur if the patient is being fed through a nasogastric tube. Since patients under treatment with IPPV are often fed in this way diagnosis may, in consequence, be delayed.

As already mentioned, gastro-oesophageal reflux is liable to occur in patients being treated by assisted ventilation. In such circumstances the regurgitated gastric contents will find their way into the trachea in the manner described.

If swallowed material or gastric contents do not pass out through the tracheostomy wound or tube they will be recognized in the tracheal aspirates. In any suspected case of tracheooesophageal fistula the aspirates should be examined for saliva, food or gastric juice.

Occasionally a communication between the trachea and the oesophagus causes abundant secretions to appear in the mouth during tracheal aspiration. These secretions are identical with the material being aspirated from the trachea, but are greater in amount. This was a feature in case 4 of Le Brigand and Roy (1966), who concluded that the material in the mouth was coughed up from the trachea through the fistula at the time of aspiration (case 12, Table I).

When food or gastric contents are aspirated into the lungs severe bronchopneumonia ensues and may well prove fatal (Fig. 4). Sometimes the opening of the tracheo-oesophageal fistula is fol- lowed by such gross aspiration into the lungs of gastric contents or swallowed material that death occurs instantaneously or rapidly from asphyxia. This occurred in six of the 44 patients collected. In slightly less severe cases the patient becomes distressed and cyanosed and may develop severe shock (Toty et al., 1967).

Another direct and characteristic consequence of tracheo-oesophageal fistula is the rapid onset of gastrointestinal distension with air, which may be rhythmical (Fig. 5). This occurred as the initial symptom in two cases (cases 27 and 38). In two other cases distension of the abdomen occurred simultaneously with the outpouring of fluid, in one through the tracheostomy tube (case 36), and in the other through the tracheostomy and nasogastric tubes, the nose, and the mouth (Fig. 5, case 39). In a fifth patient gastric distension occurred after the onset of other symptoms (case 44), while in a sixth patient 2 litres of blood were found in an enormously dilated stomach at necropsy (case 19).

In case 27 the tracheo-oesophageal fistula disclosed itself by progressive rhythmical distension of the epigastrium, caused by ventilator insufflations. This was followed by vomiting, with subsidence of the distension. The abdominal distension

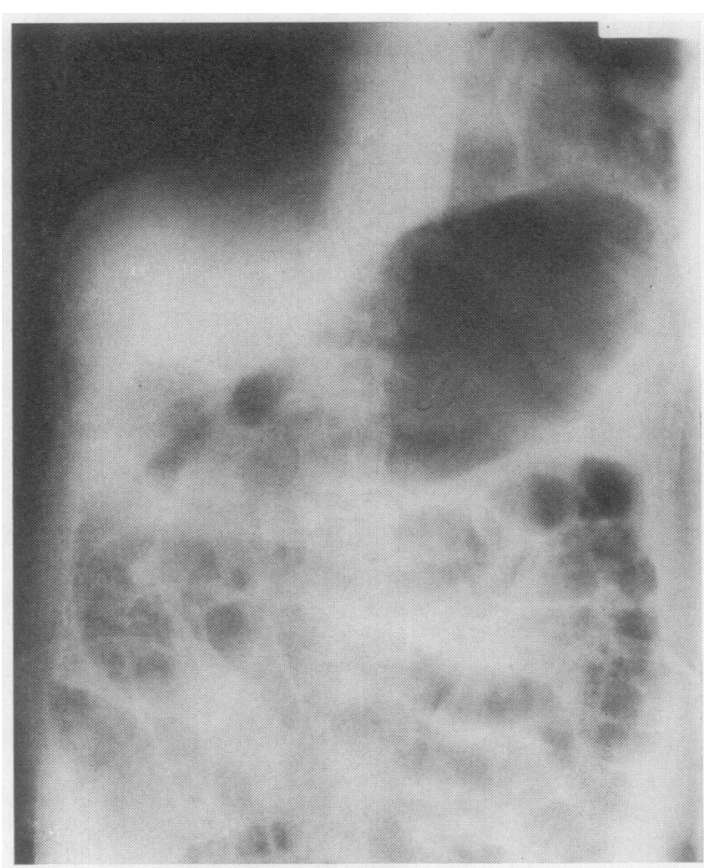

FIG. 5. Case 39. Radiograph of abdomen showing gross gaseous distension of stomach and intestines. 
was explained by the fact that the tracheooesophageal communication was found to be just below the equator of the inflated cuff of the tracheostomy tube. In case 38 the tracheo-oesophageal fistula was first manifest 95 days after performing tracheostomy by sudden, severe gastric distension. The gastrostomy tube, which had been inserted 29 days previously, was unclamped and its end was placed under water. Bubbles issued from the tube during each inspiratory phase of the ventilator. In case 36 the patient suddenly became cyanosed on the twelfth day and large amounts of fluid poured out through the tracheostomy tube. As the air passages were cleared out and ventilation was continued the abdomen suddenly became excessively distended, obviously due to insufflation of air through the tracheostomy tube. From then on gastric distension and retention, with regurgitation into the air passages, persisted despite cessation of artificial ventilation and institution of continuous suction through a nasogastric tube and gastrostomy. In case 39 radiological examination of the abdomen, at the time of an outpouring of purulent, and then bile-stained, liquid through the tracheostomy tube, nose, mouth, and nasogastric tube, showed acute dilatation of the stomach and intestines. In case 44 the abdomen became very distended with air six days after the first symptom of tracheo-oesophageal fistula, and it was found that the air could be pressed out of the stomach. In case 19 , as indicated above, distension of the stomach was found at necropsy.

Other manifestations of ulcerative tracheooesophageal fistula following tracheostomy and assisted ventilation are uncommon. Severe rapidly fatal haemorrhage was the only feature in two cases. In one of these the haemorrhage was caused by an associated fistula into the innominate artery which resulted in rapidly fatal haemoptysis (case 26). The second case (case 19) was the one mentioned in which 2 litres of blood were found in a grossly distended stomach. The patient died within a few minutes from haemorrhage into the digestive and respiratory tracts. No arterial perforation was found at necropsy. The haemorrhage had presumably occurred from granulations at the site of the tracheo-oesophageal fistula. Lesser haemorrhages may occur on occasions from this source. The second patient, shown previously as having had a perforation of the innominate artery, developed this at a later stage of the illness, after operative closure of the tracheo-oesophageal fistula and subsequent repair of an associated tracheal stenosis. He died as the result of haemor- rhage. Other complications of his original injury were also present (case 43).

Pneumothorax and pneumomediastinum rarely complicate ulcerative tracheo-oesophageal fistulae of the type under discussion, though they are more common in other varieties. This is because before the fistula occurs local mediastinitis welds the trachea and oesophagus to each other and to the surrounding tissues. The only exception of which the writer is aware is a boy of 11 years for whom total correction of Fallot's anomaly was performed by Mr. T. H. L. Rosser (case 44). On the 27th day after operation thick green pus and air escaped in great quantities from the mediastinal wound and radiological examination showed a right apical pneumothorax. The boy was thought to have suffered rupture of the trachea. A strong air leak occurred from the intercostal tube which was inserted. Milk feeds came out of the tracheostomy wound, and the abdomen became very distended with air.

There are two important warning signs that serious damage may be occurring to the trachea which may lead to ulceration and either stenosis or a tracheo-oesophageal fistula. The first of these is the necessity to use high pressures in the cuff in order to prevent air leakage. This is required when pulmonary compliance is low, and it increases the risk of damage to the trachea from pressure ischaemia. The second sign is the necessity to use increasing volumes of air to distend the cuff for the purpose of preventing air leak. This need arises because the trachea is dilating as the result of structural damage, and is an indication of ulceration and cartilage destruction. In a number of the case histories studied note was made of one or both of these features in the period before the tracheo-oesophageal fistula developed, and their occurrence should always be a cause for anxiety. Tracheobronchial infection is also often present in these cases.

In summary, high inflation pressures and increasing minimal occluding volumes should warn the clinician of damage to the trachea. The fistula may manifest itself in several ways. The commonest is the passage of swallowed material or regurgitated gastric contents into the trachea. This may result in rapid death from asphyxia, severe distress, with cyanosis and shock, or the passage of the liquid around or through the tracheostomy tube. Aspiration bronchopneumonia soon follows. Less commonly, tracheobronchial secretions are coughed up into the mouth during tracheal aspiration. Another important manifestation is rapid gaseous distension of the stomach, and perhaps 
also the intestines, which may be rhythmical. Other features, such as haemorrhage or pneumothorax, are much less common.

\section{INVESTIGATIONS}

In suspected cases the following methods of investigation are available:

1. methylene blue swallow

2. radiology

(a) radiographs of neck and upper mediastinum

(b) radiographs of chest

(c) radiographs of abdomen

(d) tracheobronchography with aqueous propyliodone (Dionosil)

(e) oesophagography with Gastrografin, Lipiodol, Hypaque, Diodone or Dionosil (but not barium)

(f) cineradiography, in association with ' $d$ ' and ' $e$ '.

3. endoscopy:

(a) tracheobronchoscopy:

(i) peroral

(ii) perstomal

(b) tracheobronchoscopy with instillation of methylene blue into pharynx or oesophagus

(c) oesophagoscopy

(d) oesophagoscopy with instillation of methylene blue through tracheostome into trachea.

METHYLENE BLUE SWALLOW This is a simple and useful test (Toty et al., 1967 ; Nicolas et al., 1967 ; Malmejac, Arnaud, Houel, and Dor, 1967 ; Hedden et al., 1969). The patient is given a solution of methylene blue in water to swallow. If a tracheobronchial fistula communicates with the trachea above the inflated cuff, or if the cuff is deflated, the methylene blue runs out of the tracheostomy wound as soon as the patient has swallowed. If the communication is below the inflated cuff the dye can be aspirated from the trachea through the tracheostomy tube immediately after swallowing.

This test cannot distinguish between the passage of dye into the trachea through a tracheo-oesophageal fistula or through the larynx. The latter will occur when there is laryngopharyngeal paralysis or dysfunction. This is not, therefore, a valid test in patients who are under treatment by IPPV because of disease of the nervous system which has resulted in laryngopharyngeal paralysis. Even in the absence of nervous disease laryngopharyngeal dysfunction is not uncommon in patients being treated by assisted ventilation, and it may develop suddenly. This occurred in a patient of mine in whom a tracheo-oesophageal fistula was suspected because swallowed liquid came out of the tracheostomy wound. The methylene blue swallow test was positive and led to further suspicion of a fistula. None was, however, present.

The methylene blue swallow test is a useful screening test, but the diagnosis of a tracheooesophageal fistula must always be confirmed by radiology and endoscopy.

RADIOLOGICAL EXAMINATION Postero-anterior radiographs should be taken of the neck and superior mediastinum, the chest, and the abdomen (Figs 4 and 5). The first of these indicate the size of the inflated cuff and the presence or absence of mediastinal and cervical subcutaneous emphysema. Marked bulging of the cuff beyond the normal confines of the trachea indicates tracheal destruction and dilatation at the site of the cuff (Fig. 4). This should already have been apparent to the clinician because of a progressive increase in the amount of air necessary for injection into the cuff to prevent an air leak. As already pointed out, pneumomediastinum and subcutaneous emphysema rarely complicate ulcerative tracheooesophageal fistula, but they often occur after the accidental and surgical varieties. The chest films will give evidence of aspiration bronchopneumonia (Fig. 4), nearly always present in greater or lesser degree, and the abdominal films may show severe gaseous distension of the stomach and intestines (Fig. 5).

An oesophagogram is useful for diagnosing both the presence and the site of a tracheo-oesophageal fistula. It may be performed with the aid of Gastrografin (Støren and Vasli, 1968), Lipiodol (Nicolas et al., 1967), Hypaque (Judd and Dubuque, 1968), Dionosil or diodone (Le Brigand and Roy, 1966), but barium should not be used as it is very irritating to the lungs and may increase the inflammation.

Tracheobronchography with aqueous Dionosil may demonstrate the tracheobronchial fistula but of ten does not do so. It is, however, of considerable value in revealing or excluding irreversible lung damage, especially in cases of some standing, and may indicate the possible need for pulmonary resection at the time of repair of the tracheooesophageal fistula (Judd and Dubuque, 1968). The examination necessitates interruption of ? IPPV (Le Brigand and Roy, 1966) and should, therefore, be carried out only by an experienced $\frac{D}{\mathbb{D}}$ clinician who has everything available to treat a respiratory problem should it arise.

Fluoroscopy and cineradiography may be combined usefully with these procedures and may add $\delta$ 
valuable information which might otherwise be missed (Le Brigand and Roy, 1966; Toty et al., 1967).

ENDOSCOPY Both oesophagoscopy and bronchoscopy should be performed in all cases to demonstrate the presence, location, and size of the fistula, to ascertain the presence or absence of necrosis and the suitability or otherwise of the fistula for operative repair, and to take a portion of granulation tissue, if present, for microscopical examination. Great care must be taken not to enlarge the fistula with the tip of the bronchoscope or oesophagoscope (Chapman and Braun, 1970). Tracheobronchoscopy may be performed perorally or perstomally, but the former is, in general, more informative (Le Brigand and Roy, 1966).

Either oesophagoscopy or bronchoscopy or both may fail to demonstrate the fistula because of the acute inflammatory reaction which surrounds it. Both examinations are more likely to succeed if a relatively large tube is present in the opposite lumen (Støren and Vasli, 1968). The tube opens out the fistula and can be seen through it at bronchoscopy or oesophagoscopy as the case may be. Another useful aid is to inject methylene blue into the opposite lumen. At oesophagoscopy the dye is injected into the trachea through the tracheostome (Le Brigand and Roy, 1966; Nicolas et al., 1967) while at bronchoscopy the dye is swallowed or instilled into the pharynx or oesophagus (Nicholas et al., 1967; Judd and Dubuque, 1968). Even if the tracheo-oesophageal fistula is not seen directly the methylene blue can easily be seen emerging through it.

Each of the above radiological and endoscopic diagnostic procedures may fail to reveal the fistula (Stephens, 1965; Chapman and Braun, 1970) so that several of them may be required to confirm the diagnosis. Their relative merits are debatable, but the findings in 28 cases of traumatic tracheooesophageal fistula collected by Chapman and Braun (1970) suggest that there is little difference between them. Thus oesophagography was diagnostic in $53 \%$ of cases examined, bronchoscopy in $57 \%$, and oesophagoscopy in $57 \%$. The high failure rate for each method taken individually is noteworthy, though their combination proved diagnostic in almost all cases. The use of methylene blue or a tube in the opposite lumen at endoscopy is not mentioned by these writers. Perhaps the figures would have been improved had they been employed.

\section{DIFFERENTIAL DIAGNOSIS}

As noted previously, patients who have had tracheostomy performed and IPPV instituted may develop tracheo-oesophageal fistulae of traumatic, surgical or ulcerative origin. Fistulae caused by closed crushing injuries nearly always follow automobile accidents, especially steering wheel injuries (Stephens, 1965; Killen and Collins, 1965 ; Judd and Dubuque, 1968; Støren and Vasli, 1968 ; Chapman and Braun, 1970), but usually do not manifest themselves for several days, when the patient is already under treatment by assisted ventilation, should this be required. Patients whose trachea and oesophagus are injured at the time of tracheostomy may also be having assisted ventilation before the condition is recognized. Thus if a patient has been treated for a crush injury of the chest of appropriate type by tracheostomy and assisted ventilation he may have a tracheooesophageal fistula of any of the three varieties. If this treatment has been instituted for conditions other than an injury he may have a surgical or ulcerative fistula. As noted previously, surgical injury, fortunately rare, is likely to occur in small children or in elderly subjects with calcified tracheal cartilages. Table II shows the main points in the differential diagnosis of the three varieties. The percentages and timings given for the traumatic variety are taken largely from Chapman and Braun (1970). Laryngopharyngeal paralysis or dysfunction must be excluded as the cause of the symptoms, for they may mimic closely a tracheo-oesophageal fistula.

\section{PREVENTION}

The preventive measures taken to avoid ulceration of the trachea are the same as those used to prevent its stenosis at cuff or tube tip level. These are discussed in detail elsewhere (Harley, 1971), and a brief summary only will be given here. In addition, further precautions must be taken to avoid other factors which may damage the oesophagus.

Mechanical damage inflicted by the cuff through pressure and movement is minimized by strict adherence to the minimal occlusive volume, avoiding frequent deflations, using thin-walled cuffs of suitable shape and length, avoiding movement of the tracheostomy tube relative to the trachea, either transmitted from the ventilator or caused by movements of the neck or body of the patient, and omitting assisted ventilation as soon as possible. Mechanical damage by the end of the tracheostomy tube is minimized by proper placement of the tracheostome and tracheostomy tube, by choosing a tube of suitable length, shape, and composition, and by avoiding movement between the tube and the trachea. 
T A B LE II

DIFFERENTIAL DIAGNOSIS OF TRACHEO-OESOPHAGEAL FISTULAE IN PATIENTS UNDERGOING TREATMENT BY TRACHEOSTOMY AND IPPV

\begin{tabular}{|c|c|c|c|}
\hline & \multicolumn{3}{|c|}{ Tracheo-oesophageal Fistula } \\
\hline & Traumatic & Surgical & Ulcerative \\
\hline $\begin{array}{l}\text { Circumstances } \\
\text { of occurrence }\end{array}$ & $\begin{array}{l}\text { Tracheostomy } \\
\text { and IPPV for } \\
\text { injury, usually } \\
\text { automobile } \\
\text { accident of } \\
\text { steering-wheel } \\
\text { type }\end{array}$ & $\begin{array}{l}\text { Tracheostomy } \\
\text { and IPPV for } \\
\text { any condition }\end{array}$ & $\begin{array}{l}\text { Tracheostomy } \\
\text { and IPPV for } \\
\text { any condition }\end{array}$ \\
\hline Sex & $\begin{array}{l}\text { Almost always } \\
\text { males }\end{array}$ & Either sex & Either sex \\
\hline Age & $\begin{array}{l}\text { Young, usually } \\
\text { under } 35 ; \text { very } \\
\text { rarely over } 40\end{array}$ & $\begin{array}{l}\text { Usually young } \\
\text { children or } \\
\text { elderly sub- } \\
\text { jects with } \\
\text { calcified } \\
\text { tracheal } \\
\text { cartilages }\end{array}$ & $\begin{array}{l}\text { Any age; } \\
\text { fairly even } \\
\text { distribution } \\
\text { between } 20 \\
\text { and } 70\end{array}$ \\
\hline $\begin{array}{l}\text { Time of onset } \\
\text { of symptoms }\end{array}$ & $\begin{array}{l}\text { Usually } 3 \text { to } 5 \\
\text { days; occasion- } \\
\text { ally immediate or } \\
\text { up to } 20 \text { days }\end{array}$ & $\begin{array}{l}\text { Usually first } \\
48 \text { hours }\end{array}$ & $\begin{array}{l}\text { Usually 2nd to } \\
\text { 10th week, } \\
\text { especially 2nd } \\
\text { to 4th week; } \\
\text { occasionally } \\
\text { up to } 18 \\
\text { months }\end{array}$ \\
\hline $\begin{array}{l}\text { Mediastinal } \\
\text { or sub- } \\
\text { cutaneous } \\
\text { emphysema } \\
\end{array}$ & Common $(54 \%)$ & Common & Rare \\
\hline Pneumothorax & $\begin{array}{l}\text { Fairly common } \\
(25 \%)\end{array}$ & Uncommon & Rare \\
\hline Rib fracture & $28 \%$ & $\begin{array}{l}\text { Absent (unless } \\
\text { injury) }\end{array}$ & $\begin{array}{l}\text { Absent (unless } \\
\text { injury) }\end{array}$ \\
\hline Location & $\begin{array}{l}\text { Usually at or just } \\
\text { above carina; } \\
\text { rarely in neck }\end{array}$ & $\begin{array}{l}\text { Site of } \\
\text { tracheal stoma }\end{array}$ & $\begin{array}{l}\text { Site of inflated } \\
\text { cuff }\end{array}$ \\
\hline Pathology & $\begin{array}{l}\text { Longitudinal } \\
\text { tear, slit-like or } \\
\text { oval, in long axis } \\
\text { of trachea and } \\
\text { oesophagus }\end{array}$ & Clean incision & $\begin{array}{l}\text { Ulcerative } \\
\text { process, } \\
\text { usually larger } \\
\text { in trachea than } \\
\text { oesophagus }\end{array}$ \\
\hline $\begin{array}{l}\text { Tolerance of } \\
\text { patient }\end{array}$ & Good & $?$ & Bad \\
\hline
\end{tabular}

Infection is reduced to a minimum by strict asepsis and avoidance of tight suturing of the wound at tracheostomy, the use of dry, sterile dressings, gentle and aseptic tracheobronchial aspiration, proper and aseptic control of the temperature and humidity of the gases delivered to the trachea, the use of antibiotics therapeutically, but not prophylactically, and perhaps also barrier nursing.

The use of tracheostomy tubes made of chemically irritant materials and of anti-inflammatory agents should be avoided and all precautions taken to obviate, or to treat energetically, periods of arterial hypotension.

Nasogastric tubes, if used, should be as small and soft as function will allow and should be withdrawn as early as possible. Gastro-oesophageal reflux can be minimized by avoiding, as far as possible, the horizontal posture, nasogastric tubes, and muscle relaxants.

\section{TREATMENT}

When a tracheo-oesophageal fistula is diagnosed the chief problems which arise are ventilation of the patient, nutrition of the patient, control of infection, and closure of the fistula. Since only a minority of fistulae close spontaneously (vide infra) surgical closure must be the aim. The timing and technique of this will be described.

VENTILATION Ventilation of the patient poses a considerable problem, both before and after closure of the fistula, since most ulcerative fistulae are caused primarily by damage inflicted by the inflated cuff. In many patients adequate ventilation cannot be maintained through the resident tracheostomy tube because of the development of a considerable air leak, a difficulty which may be accentuated by insufflation of the stomach and intestines. In some cases adequate ventilation may be re-established, before closing the fistula, by changing the tracheostomy tube for a longer one with a single cuff (Flege, 1967 ; Toty et al., 1967 ; Hedden et al., 1969) or for one with a double cuff (Otteni et al., 1967; Støren and Vasli, 1968). These methods are not always successful.

Since the cuff is usually responsible for the fistula it would seem logical to deflate it, provided adequate ventilation can be maintained. If so, the cuffed tube may be replaced by a non-cuffed one of silver or plastic. It is essential to keep a tube in situ while the patient is being prepared for surgery so that efficient tracheobronchial aspirations can be maintained (Le Brigand and Roy, 1966).

NUTRITION In all cases the oesophagus must be rested and oral or gastric contents denied access $N$ to the trachea, in so far as is possible, by feeding $N$ through a nasogastric, gastrostomy or jejunostomy tube (Malmejac et al., 1967). Although adequate $\omega$ nutrition can usually be achieved by one or other 2 of these methods, none of them always prevents $\stackrel{O}{\subset}$ reflux of gastric contents through the fistula into $\mathbb{D}$ the trachea (Le Brigand and Roy, 1966; Malmejac et al., 1967). A nasogastric tube failed to prevent tracheal aspiration or progressive gastric distension in seven out of 15 cases in this series, gastrostomy was unsuccessful in three out of seven cases, and $\triangle$ jejunostomy was unsuccessful in two out of three 
cases. A tube, however, avoids the need to swallow liquids (other than saliva), which pass through the fistula into the trachea and flood the bronchial tree. As pointed out previously, nasogastric tube feeding may delay the diagnosis of a tracheooesophageal fistula by eliminating oral feeds. In case 23 the fistula was first recognized 32 days after tracheostomy when an oral feed, given after withdrawal of the nasogastric tube, came out of the tracheostomy wound.

If a nasogastric tube is employed the feed should be given as a drip in order to reduce to a minimum the reflux of gastric contents, and the tube should be as narrow and as soft as is consistent with function.

There is difference of opinion as to the relative merits of gastrostomy and jejunostomy feeding, but some degree of gastric retention seems to be common in these patients. When this is so gastrostomy feeding is poorly tolerated and the feeds are liable to regurgitate (Støren and Vasli, 1968). Dor (1966) feels that, in the presence of severe inflammation around the fistula, gastrostomy is preferable to operative repair, and he advises advancing the tube through the pylorus into the duodenum. Lortat-Jacob (1966) thinks that in the case of oesophageal wounds jejunostomy is safer than gastrostomy because it is associated with less reflux into the oesophagus. He employs an en $Y$ or Witzel technique and advises that it be performed 30 to $40 \mathrm{~cm}$ below the duodenojejunal junction in order to avoid traction on the first loop of the jejunum. Great care must be taken to avoid obstructing the bowel.

If all the above methods fail to prevent serious gastric reflux and bronchial aspiration, oesophageal exclusion may have to be considered (Le Brigand and Roy, 1966) if operative closure of the fistula either fails or has to be deferred.

CONTROL OF INFECTION AND OTHER CONSERVATIVE MEASURES Control of infection is essential either to eliminate or to localize it, and to reduce the inflammation of the tissues around the fistula as much as possible. The appropriate antibiotics should be selected for this purpose. Other supportive measures, such as blood transfusion, should be used as required.

SPONTANEOUS CLOSURE OF TRACHEO-OESOPHAGEAL FISTULAE

Spontaneous closure of all varieties of tracheooesophageal fistulae in patients undergoing treatment by tracheostomy and IPPV is uncommon.
Chapman and Braun (1970), reporting on 28 collected cases of the traumatic variety following closed chest injury (one of which, that of Støren and Vasli (1968), was, in my opinion, an ulcerative fistula), confirmed the statement of previous writers that spontaneous closure does not occur, and both their patients in whom operative repair was not attempted died. Judd and Dubuque (1968) collected 148 cases of benign, acquired oesophagotracheobronchial fistulae due to various causes, mostly inflammatory, and stated that spontaneous closure was rare. Of 127 cases reviewed by Anderson and Sabiston (1965), adequate information regarding treatment and results was obtained in 94. Five of these underwent spontaneous cure. Le Brigand and Roy (1966), writing on ulcerative fistulae, stated that they knew of only one case of spontaneous cure. Among the 44 cases of ulcerative fistulae reviewed here, seven out of 24 recovered without operation, but four of these were among the five cases of Toty et al. (1967). These workers appear to have a unique success rate of closure with conservative treatment.

\section{SURGICAL TREATMENT}

Since spontaneous closure of tracheo-oesophageal fistulae is so uncommon operative closure should be the aim. Nicolas et al. (1967) consider the results of operation to be discouraging and they lay stress on preventive measures, conceding that their practical application remains difficult.

A number of aspects of surgery merit discussion, such as the correct time for operation, the operative approach, the repair procedure, the complications, and the mortality.

TIME FOR OPERATION In the past there has been a tendency to defer operative closure of tracheooesophageal fistulae for a number of weeks in order to control infection and necrosis, and to allow the margins of the fistula to become firm enough to hold sutures, but recently earlier closure has been advocated.

With regard to traumatic fistulae, Stephens (1965) states that ideally closure should be performed within seven to 10 days of the onset of symptoms, but that if the diagnosis is made later, or the general condition is too bad, gastrostomy or jejunostomy should be performed and operative closure deferred for about one month, so as to allow inflammation and necrosis of the tissues to resolve. Støren and Vasli (1968) state that as spontaneous closure of traumatic fistulae never 
occurs operative closure should be planned as soon as the diagnosis is made, but that no generalization should be made as to the correct time. They agree with Stephens (1965) that if the diagnosis is made early operation may be performed in the first 10 days. Severe inflammation or necrosis at the site of the fistula, however, contraindicate surgery, for in their presence the sutures cut out. According to these workers, if the operation cannot be performed early it should be delayed for eight to 10 weeks. Chapman and Braun (1970), also referring to traumatic fistulae, advise operation as soon as the diagnosis has been confirmed ; ideally, this means during the first few days after the onset of symptoms. In my view surgical fistulae should be closed as soon as the diagnosis is made, while the tissues are still healthy and before bronchopneumonia has developed.

Ulcerative fistulae differ from traumatic ones in two important respects, namely, in their pathology and in the tolerance of the patient to their presence. In traumatic fistulae the surrounding tissues are at first relatively healthy, severe inflammation and necrosis occurring only later if the fistula is not closed. Ulcerative fistulae occur in consequence of pressure-infective necrosis and the tissues are severely inflamed and necrotic before the fistula opens. The other difference is that traumatic fistulae are well tolerated for relatively long periods, whereas ulcerative ones are not. For these reasons the timing of treatment of one type does not necessarily apply to the other. Late closure of traumatic fistulae seems to give better results if operation cannot be performed in the first days (Stephens, 1965; Støren and Vasli, 1968 ; Le Brigand and Roy, 1966) because tolerance is good and the patient can be kept in a satisfactory general condition.

In estimating the best time for operative closure of an ulcerative fistula the following factors must be considered:

(1) the condition of the tissues around the fistula

(2) the general condition of the patient

(3) the necessity for continuing IPPV

(4) the success or otherwise of maintenance of nutrition

(5) ability to control orotracheal aspiration

(6) ability to control gastrotracheal aspiration

(7) ability to control pulmonary infection.

The condition of the tissues around the fistula is of great importance and must be assessed by both tracheoscopy and oesophagoscopy. Severe inflammation or necrosis of the tissues, or the presence of diffuse mediastinitis or mediastinal abscess, make operative closure both difficult and dangerous (Stephens, 1965 ; Le Brigand and Roy, 1966; Dor, 1966; Støren and Vasli, 1968) and contraindicate the operation. If these conditions are present operation must be deferred until they have been controlled by the methods already discussed.

Inability to maintain assisted ventilation, despite the fact that the patient continues to require it, may force the surgeon to attempt closure of the fistula even though the time is, for other reasons, inappropriate.

The general condition of the patient may influence the decision for or against operation. In some cases overwhelming tracheobronchial flooding may kill the patient before operation can be arranged, while in others severe bronchopneumonia may contraindicate surgery until it can be controlled.

The success or failure of nasogastric drip feeding, gastrostomy or jejunostomy in maintaining nutrition and in controlling the aspiration of oral or gastric contents into the lungs are matters of the utmost importance for patients in whom immediate surgery is contraindicated. Their failure may force the surgeon to intervene at an inopportune time.

The toleration of the patient to his fistula is important but variable. In general, traumatic fistulae are tolerated better than the ulcerative type and, in consequence, they allow of more latitude in management and do not require closure so urgently.

Severe bronchopulmonary infection, common in these patients, must be assessed and the ability to control it without closure of the fistula estimated. As long as the fistula is open this is a difficult matter.

In summary, operative closure of the fistula must be planned as soon as the diagnosis is confirmed, but its timing is a matter of difficulty, requiring critical judgement. The operation should be performed as soon as the tissues are healthy enough and the patient is fit enough. Rapid death may exclude the possibility, while inability to control the factors enumerated above may force the surgeon to operate before the patient or his tissues are in a suitable state.

SURGICAL TECHNIQUE The operative approach depends upon the level of the fistula. The great majority of ulcerative fistulae occur at the site of the cuff, situated 1 to $3 \mathrm{~cm}$ below the tracheostome and at, or just below, the upper margin of the manubrium sterni. Most can be exposed satisfactorily by an incision along the anterior border 
of the left sternomastoid muscle (Le Brigand and Roy, 1966; Dor, 1966; Malmejac et al., 1967 ; Nicolas et al., 1967), if necessary extended down the mid-line over the upper portion of the sternum, which is divided. This extension is not usually required. Alternatively, a collar incision may be used (Schulthess, 1964, case 43), but, in my opinion, the fistula is better approached from the left side than from in front, for from the anterior approach the oesophagus is obscured by the trachea. This does not apply to tracheal resection for stenosis. When fistulae are sited lower down, usually in post-traumatic examples, a high right thoracotomy is preferable. Before incising the neck the tracheostomy opening must be excluded from the field of operation.

After making the incision along the anterior border of the left sternomastoid muscle the carotid sheath is retracted outwards to expose the trachea and oesophagus. The laryngotracheal mass is then retracted forwards and the oesophagus is retracted backwards with the aid of slings of tape or fine rubber tubing. The oesophagus and trachea are often firmly adherent in the neighbourhood of the fistula and their dissection and separation may be difficult. They should be separated and retracted from each other both above and below the fistula, care being taken not to injure the recurrent nerves.

In all cases the trachea and oesophagus must be closed individually. Suturing of the oesophagus is usually easy, but closure of the membraneous trachea is often much more difficult (Le Brigand and Roy, 1966 ; Dor, 1966 ; Malmejac et al., 1967) because of ulceration and necrosis, and reinforcement is always required by interposition of viable tissue. If much necrosis is present suture of the tracheal tissues may be impossible and a graft must be relied upon for closure of the fistula.

The oesophagus is best closed transversely with two layers of interrupted sutures, one through the mucous membrane, the other through the muscular coat. If this cannot be done a single layer of sutures is usually satisfactory. The trachea is also best closed transversely, with a single layer of interrupted or mattress sutures. Silk or nylon may be used for the oesophagus, and silk, nylon or steel wire for the trachea. Care must be taken not to stenose either structure. The suture line in the trachea is then reinforced, preferably with a pedicled muscle graft which is sutured to it and interposed between the trachea and the oesophagus. Muscles successfully used in this way are the sternomastoid (Le Brigand and Roy, 1966; Flege, 1967 ; Nicolas et al., 1967), the sternothyroid (Nicolas et al., 1967; Malmejac et al., 1967), and the inferior belly of the omohyoid (Le Brigand and Roy, 1966; Dor, 1966; Nicolas et al., 1967 ; Malmejac et al., 1967). The last of these is the most appealing. Alternatively, a pedicled skin flap may be employed (Schulthess, 1964 ; Le Brigand and Roy, 1966; case 41 of the present series), but muscle is easier to use and is as effective. In my opinion, pleura (Støren and Vasli, 1968) or fascia lata (Le Brigand and Roy, 1966) are not as suitable as muscle. If suture of the trachea proves impossible, because of inflammatory softening or necrosis, the muscle flap is sutured to the edges of the opening in it so as to seal it as effectively as possible.

Drainage of the region of the fistula is essential, preferably with the aid of suction (Malmejac et al., 1967). If satisfactory closure of the trachea and oesophagus has been achieved a nasogastric tube is passed into the stomach and the patient is fed through this for a week. If closure is unsatisfactory or impossible gastrostomy or jejunostomy should be performed and, if necessary, cervical oesophagostomy should be added (Flege, 1967).

COMPLICATIONS OF SURGERY The complications recorded in this review were recurrent nerve paralysis (case 9), tracheal stenosis (cases 8, 12, 22, and 41), uncontrollable infection with Pseudomonas pyocyanea (case 17), recurrent tracheooesophageal fistula (case 43), and inability to repair the fistula (case 10).

\section{MORTALITY}

Among the 44 cases in this review, 12 are known to have had operative repair of the fistula and 24 are known not to have had operative repair. Details are not available for the remaining eight patients. Table III shows the findings for the 36 cases for which details are known.

\section{T A B L E I I I}

MORTALITY FOR 36 PATIENTS WITH ULCERATIVE TRACHEO-OESOPHAGEAL FISTULAE FOLLOWING TREATMENT BY TRACHEOSTOMY AND IPPV, ACCORDING TO

\begin{tabular}{l|c|ccc|c}
\multicolumn{1}{c|}{$\begin{array}{c}\text { Method of } \\
\text { Treatment }\end{array}$} & No. & Recovered & $\begin{array}{r}\text { Result } \\
\text { Dot known }\end{array}$ & $\begin{array}{c}\text { Mortality } \\
(\%)\end{array}$ \\
\hline Conservative & $24^{1}$ & $7^{2}$ & 17 & 0 & $70 \cdot 8$ \\
Operative repair & 12 & 6 & 5 & 1 & 45.5 \\
\hline
\end{tabular}

${ }^{1}$ Six of the 24 patients not operated upon died within minutes so that no useful treatment could be instituted; 11 of the remaining 18 patients died, a mortality of $61 \%$.

Four of the seven recoveries from conservative treatment were among five cases reported by Toty et al. (1967).

As shown, the mortality for the patients operated upon was $45.5 \%$, as opposed to $70 \cdot 8 \%$ 
for those treated without operative closure. However, in the latter group of 24 patients six died so rapidly from flooding of the tracheobronchial tree that no useful treatment could be administered. Of the remaining 18 patients, 11 died, a mortality of $61 \%$. It is surprising that seven of these patients should have recovered without operation, for it is the general opinion that without surgery tracheo-oesophageal fistulae rarely close spontaneously and have a very high mortality. It is of interest that no fewer than four of the seven recoveries were among the five patients treated by Toty et al. (1967). Apart from these workers, who had a recovery rate of $80 \%$, the mortality for conservative treatment of ulcerative fistulae has been very high, and I have little doubt that the fistulae should be closed surgically whenever possible. Death occurs too rapidly in one case in six to allow of this being done. In those who survive the establishment of a fistula the time for operation must be carefully chosen, and efficient care of the patient both before and after surgery is essential.

My grateful thanks are due to my colleagues in the London Society of Thoracic Surgeons, Mr. T. H. L. Rosser, and Dr. D. Ball, for allowing me to use their cases, and to Dr. D. Ball for providing me with necropsy specimens and radiographs of his two patients for illustration in Figs 1, 4, and 5. My thanks are due also to Miss C. Peake, Department of Medical Illustration, Cardiff Royal Infirmary, for drawing Figs 2 and 3, and to the Department of Photography, Llandough Hospital, for reproducing Figs 1, 4, and 5. I am also indebted to Mrs. P. Chorley for typing the manuscript.

\section{REFERENCES}

Atherstone, R. N. G., and Ryder, G. H. (1967). Endotracheal intubation or tracheostomy? Lancet, 1, 437.

Anderson, R. P., and Sabiston, D. C. (Jr.) (1965). Acquired bronchoesophageal fistula of benign origin. Surg. Gynec. Obstet., 121, 261.

Bargh, W., and Slawson, K. B. (1965). Experience of an artificial ventilation unit. Brit. J. Anaesth., 37, 574.

Bryant, L. R. (1968). Discussion of Pearson, F. G., Goldberg, M., and da Silva, A. J. (1968). Tracheal stenosis complicating tracheostomy with cuffed tubes. Arch. Surg., 97, 380 .

Campbell, D. (1968). Trauma to larynx and trachea following intubation and tracheostomy. J. Laryng., 82, 981.

Chapman, N. D., and Braun, R. A. (1970). The management of tracheo-esophageal fistula caused by blunt chest trauma. Arch. Surg., 100, 681.

Crosby, W. M. (1964). Automatic intermittent inflation of tracheostomy-tube cuff. Lancet, 2, 509.
Deverall, P. B. (1967). Tracheal stricture following tracheostomy. Thorax, 22, 572.

Dor, J. (1966). Discussion of Le Brigand, H., and Roy, B. (1966).

Flege, J. B. (Jr.) (1967). Tracheoesophageal fistula caused by cuffed tracheostomy tube. Ann. Surg., 166, 153.

Glas, W. W., King, O. J. (Jr.), and Lui, A. (1962). Complications of tracheostomy. Arch. Surg., 85, 56.

Harley, H. R. S. (1971). Laryngotracheal obstruction com- $\overrightarrow{0}$ plicating tracheostomy or endotracheal intubation with assisted respiration: a critical review. Thorax, 26, 493.

Hedden, M., Ersoz, C. J., and Safar, P. (1969). Tracheoesophageal fistulas following prolonged artificial $\overrightarrow{2}$ ventilation via cuffed tracheostomy tubes. Anesthesiology, 31, 281.

Hunter, A. R. (1967). Tracheal stenosis. In: Recent Advances in Anaesthesia and Analgesia, edited by C. L. Hewer, 10th ed., p. 188. Churchill, London.

Johnston, J. B., Wright, J. S., and Hercus, V. (1967). Tracheal 윽 stenosis following tracheostomy-a conservative approach to treatment. J. thorac. cardiovasc. Surg., 53, Z 206.

Judd, D. R., and Dubuque, T. (1968). Acquired benign esophagotracheobronchial fistula. Dis. Chest, 54, 237.

Killen, D. A., and Collins, H. A. (1965). Tracheoesophageal N fistula resulting from non-penetrating trauma to the chest. J. thorac. cardiovasc. Surg., 50, 104.

Le Brigand, H., and Roy, B. (1966). Fistules trachéooesophagiennes après trachéotomie. A propos de $\overline{0}$ quatre observations. Mém. Acad. Chir., 92, 405.

Lord, R. (1967). Review of 280 tracheostomies. Aust. N.Z. Ф J. Surg., 36, 192.

Lortat-Jacob (1966). Discussion of Le Brigand, H., and Roy, B. (1966).

Malmejac, C., Arnaud, A., Houel, J., and Dor, J. (1967). Note à propos des fistules oeso-trachéales après trachéotomie. Ann. Chir. thorac. cardiovasc., 6, 1167.

Mounier-Kuhn, P., Gaillard, J., Garing, P., and Rebattu, J. P. (1958). Ulcères de contact oesophagiens et $\stackrel{0}{x}$ trachéaux. J. franç. Oto-rhino-laryng., 7, 851.

Nicolas, F., Dupon, H., Guillon, J., and Cornet, E. (1967). Fistules trachéo-oesophagiennes après trachéotomie. À propos de trois observations. Ann. Chir. thorac. cardio-윽 vasc., 6, 1159.

Otteni, J. C., Morand, G., Tempe, J. D., Miech, G., and $\frac{\mathrm{O}}{\partial}$ Witz, J. P. (1967). Complications de la trachéotomie. Les fistules trachéo-oesophagiennes. Ann. Chir. thorac. cardiovasc., 6, 1149.

Schulthess, G. von (1964). Tracheotomie; Komplikationen N und Spätfolgen. Fortschr. Hals-Nas.-Ohrenheilk., 11, 51.

Stephens, T. W. (1965). Traumatic tracheo-oesophageal fistula following steering-wheel type of injury. Brit. J. Surg., 52, 370.

Stiles, P J. (1965). Tracheal lesions after tracheostomy. Thorax, 20, 517.

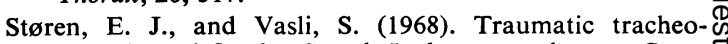
oesophageal fistula. Scand. J. thorac. cardiovasc. Surg., 2, 43.

Toty, L., Hertzog, P., Diane, Ch., and Aboudi, A. (1967). Cinq cas de fistules trachéo-oesophagiennes après $\bigcirc$ trachéotomie. Ann. Chir. thorac. cardiovasc., 6, 1155.

Watts, J. McK. (1963). Tracheostomy in modern practice. Brit. J. Surg., 50, 954. 